\title{
Case Report \\ Optimal Tilt and Orientation Angles in Fixed Flat Surfaces to Maximize the Capture of Solar Insolation: A Case Study in Ecuador
}

\author{
Xavier Serrano-Guerrero ${ }^{1}\left[\right.$, Eduardo Cantos ${ }^{1}$, Juan-Javier Feijoo ${ }^{1}$, Antonio Barragán-Escandón ${ }^{1}[0$ \\ and Jean-Michel Clairand ${ }^{2, *(\mathbb{D})}$ \\ 1 Grupo de Investigación en Energías, Universidad Politécnica Salesiana, Cuenca 010103, Ecuador; \\ jserranog@ups.edu.ec (X.S.-G.); ecantosa@est.ups.edu.ec (E.C.); jfeijool@ups.edu.ec (J.-J.F.); \\ ebarragan@ups.edu.ec (A.B.-E.) \\ 2 Facultad de Ingeniería y Ciencias Aplicadas, Universidad de las Américas-Ecuador, Quito 170122, Ecuador \\ * Correspondence: jean.clairand@udla.edu.ec; Tel.: +593-9-95860613
}

\section{check for}

updates

Citation: Serrano-Guerrero, X.;

Cantos, E.; Feijoo, J.-J.;

Barragán-Escandón, A.; Clairand,

J.-M. Optimal Tilt and Orientation

Angles in Fixed Flat Surfaces to

Maximize the Capture of Solar

Insolation: A Case Study in Ecuador.

Appl. Sci. 2021, 11, 4546. https://

doi.org/10.3390/app11104546

Academic Editors: Harry D.

Kambezidis and Basil E. Psiloglou

Received: 13 April 2021

Accepted: 7 May 2021

Published: 17 May 2021

Publisher's Note: MDPI stays neutral with regard to jurisdictional claims in published maps and institutional affiliations.

Copyright: (c) 2021 by the authors. Licensee MDPI, Basel, Switzerland. This article is an open access article distributed under the terms and conditions of the Creative Commons Attribution (CC BY) license (https:// creativecommons.org/licenses/by/ $4.0 /)$.

\begin{abstract}
Due to the increasing attention of PV generation, and to the uncertainty of the real PV electrical power output, power system are facing planning challenges. Hence, this case report proposes a computer application that determines the optimal tilt and orientation angles of flat surfaces to maximize solar insolation capture based on existing mathematical models. The study uses data from different meteorological variables measured and estimated through a typical year from the most populated Ecuador cities. The computer application considers the global, diffuse, direct, reflected radiation, and the angle of incidence of the sun. This analysis reveals the angle of inclination and orientation where the highest percentage of insolation is obtained in Ecuador's main cities. The results suggest that, in Ecuador, flat solar capture surfaces can be oriented between $20^{\circ}$ and $60^{\circ}$ concerning north, and with tilt angles between $12^{\circ}$ and $19^{\circ}$. This contrasts with the literature, which recommends an orientation to the equator and an inclination equal to the location's latitude.
\end{abstract}

Keywords: inclination angle; orientation angle; solar irradiance; tilted surface; transposition models

\section{Introduction}

The share of renewable energies (REs) in power systems is growing continuously due to various concerns [1]. In particular, by the use of photovoltaic (PV) panels, solar energy is one of the most popular RE and has gained increasing attention. Unlike some other sources of electricity, it is not possible to run out of solar power. Moreover, the maintenance costs for PV generation are relatively low. However, some challenges have still to be considered. For example, it is difficult to predict solar generation due to weather uncertainties [2]. Today, many PV-based microgrids are implemented, which could be isolated from the main grid. However, microgrids suffer more important stability issues. Thus, it is essential to guarantee the maximum electricity power [3].

For the optimum generation planning of typical grid systems or microgrids based on PV, it is essential to determine the installation site's PV performance. The amount of power generated by a PV panel depends on the sunlight to which it is exposed to. Thus, it is crucial to maximizing the PV panel's sunlight by orienting optimally. Various mathematical models have, in fact, been developed based on available climate data to estimate the availability of solar energy.

In PV studies, various main factors must be considered, such as weather conditions, orientation (azimuth angle), and horizontal inclination angle (related to the ground). The latter could vary depending on the year, month and day due to the sun's position. All this to achieve optimal performance in terms of capture. The variables associated with the positioning and orientation of the panels can drastically modify the system's performance. The mathematical models of solar trajectory relate a group of variables, which are necessary 
to refer to the measurements as field parameters in irradiance with those that affect directly in a normal way on the capture surface [4]. This provide valuable information of design, such as optimal panel arrangement for the highest energy capture [5,6].

The transposition models could be divided into two groups: isotropic and anisotropic. Isotropic models consider that the total sky diffuse radiation is distributed isotropically over the sky dome [7]. Anisotropic models assume isotropic components with an additional circumsolar region or the horizon-brightening components. Anisotropic models could include two or three components.

Various models have evaluated the accuracy transposition models by comparing the modeled irradiance with measured values in different climate conditions since long time ago. For example, in Reference [8], the calculation of monthly mean solar radiation for horizontal and inclined surfaces was proposed. Gueymar et al. [9] proposed a radiation model, titled CDRS, which can be used with different input data combinations. In Reference [10], an assessment of tilted insolation models in Athens, Greece, was performed.

Some recent models have been proposed. For example, Housmans et al. [11] proposed an inverse process of transposition models by converting from tilted to horizontal. In [12], an open-loop single-axis solar tracking system that tracks the sun through optimized rotation about the tilted axis was presented. Halilovic et al. [13] performed an analytical approach for determining the global horizontal from the global tilted irradiance. In Reference [14], a solar gridded model was proposed using spatial and temporal data in Nordic countries. Gomez-Uceda et al. [15] investigated the influence of terrain orientation for PV systems.

Many other works compared the performance of available transposition models in various countries, such as Thailand [16], Algeria [17,18], Greece [19], Slovenia [20], Germany [21], Palestine [22], Spain [23], and Brazil [24].

Due to geographic location conditions, Ecuador is at a latitude in which the solar potential is particular and vital $[25,26]$. Ecuador is a developing country with increasing energy consumption and seasonality with little variation throughout the year [27]. Consequently, there are relatively constant high levels of insolation. Furthermore, it has excellent potential for using solar energy as an alternative for the effective reduction of atmospheric pollutants and the global effects of climate change [28,29]. Several studies were carried out in Ecuador to obtain the optimal position of a solar panel. For example, the authors of Reference [30] suggest an orientation of $35^{\circ}$ concerning the north and an inclination of $15^{\circ}$ concerning the horizontal, for the city of Cuenca. In cities where there are significant changes in weather conditions across cities due to geographic conditions, it is not representative for the entire country to estimate a single average optimum tilt angle. Thus, this work proposes the development of an computer application to obtain the optimal orientation and inclination of a flat surface, based on data acquired from meteorological stations in the city of Cuenca and Typical Meteorological Years (TMY) files within the different cities of Ecuador.

The main contributions of this article are listed as follows:

- $\quad$ Five irradiance transposition models are used to calculate the capture of solar insolation

- Various cities in Ecuador are studied to assess the impact of the location in the capture of solar insolation

- The performance of each model is evaluated in the selected cities

The rest of the paper is organized as follows: Section 2 presents the methodology. Section 3 discusses the main results. Finally, Section 4 is devoted to conclusions.

\section{Materials and Methods}

The methodology of this work is based on the application of five well-known mathematical models. These models estimate the amount of solar irradiance that can be captured on a flat surface for different orientations and tilt angles. The models' input data are the beam, diffuse, and global irradiance on a horizontal surface, the orientation, and tilt angles of the capturing flat surface. Then, each model obtains as output the amount of solar 
irradiance captured for different positions. In this way, it is possible to know the optimal position of a flat surface to capture solar energy at a given location.

To determine the optimal position of flat surfaces, various parameters should be taken into account, which are listed as follows:

- Solar insolation: The amount of solar radiation received from the Sun and expressed in $\mathrm{Wh} / \mathrm{m}^{2}$.

- Solar irradiance: The instantaneous power per unit area received from the Sun on the Earth's surface and expressed in $\mathrm{W} / \mathrm{m}^{2}$. The irradiance is measured in the wavelength range of the measuring instrument.

- Ground reflectance (albedo): The portion of solar insolation incident on the ground that is reflected.

- Sky clarity index: The ratio of measured insolation relative to insolation outside the atmosphere calculated in the given location.

The analyzed data in Cuenca was collected from a meteorological station located in the Salesian Polytechnic University. The weather data were obtained using VAISALA weather station, Datalogger QML201C, and the VAISALA HydroMetTM Automatic Weather Station Client Software (AWS Client). The AWS Client includes outlier detection as a tool of Quality Control. The data collected is from a VAISALA weather station with a data logger QML201C. The weather station is exposed directly to the environment. The meteorological data are transmitted to a PC station with VAISALA HydroMetTM Automatic Weather Station Client Software (AWS Client), a graphical and end-user software. The time interval of the data is $15 \mathrm{~min}$. The solar radiation is measured with a Hukseflux thermal sensor SR11, HFS Shadow-Ring.

The authors have selected Ecuador's case study since, firstly, we had the available information of the most populated cities in the country that are distributed in different regions. Moreover, this is a particularly interesting case study since the equatorial line crosses the country, so the influence of the local climate and the geographical position can influence the optimal orientation and inclination of the solar insolation capturing surfaces. The characteristics of the selected cities are summarized in Table 1 and the corresponding map is depicted in Figure 1.

Table 1. Characteristics of the selected cities in Ecuador.

\begin{tabular}{llllll}
\hline City & $\begin{array}{l}\text { Population } \\
\text { [millions] }\end{array}$ & Latitude $\left[{ }^{\circ}\right]$ & Longitude $\left[{ }^{\circ}\right]$ & Elevation $[\mathrm{m}]$ & Data Source \\
\hline Quito & 2 & -0.22 & -78.51 & 2850 & TMY file \\
Guayaquil & 2.7 & -2.2 & -79.9 & 4 & TMY file \\
Cuenca & 0.34 & -2.88 & -79.02 & 2550 & Vaisala Weather \\
& & & & & Station \\
Machala & 0.24 & -3.26 & -79.96 & 6 & TMY file \\
Loja & 0.29 & -4 & -79.2 & 2060 & TMY file \\
Santo & 0.27 & -0.25 & -79.17 & 635 & TMY file \\
$\begin{array}{l}\text { Domingo } \\
\text { Portoviejo }\end{array}$ & 0.21 & -1.06 & -80.47 & 53 & \\
Ambato & 0.17 & -1.24 & -78.63 & 2580 & TMY file \\
\hline
\end{tabular}




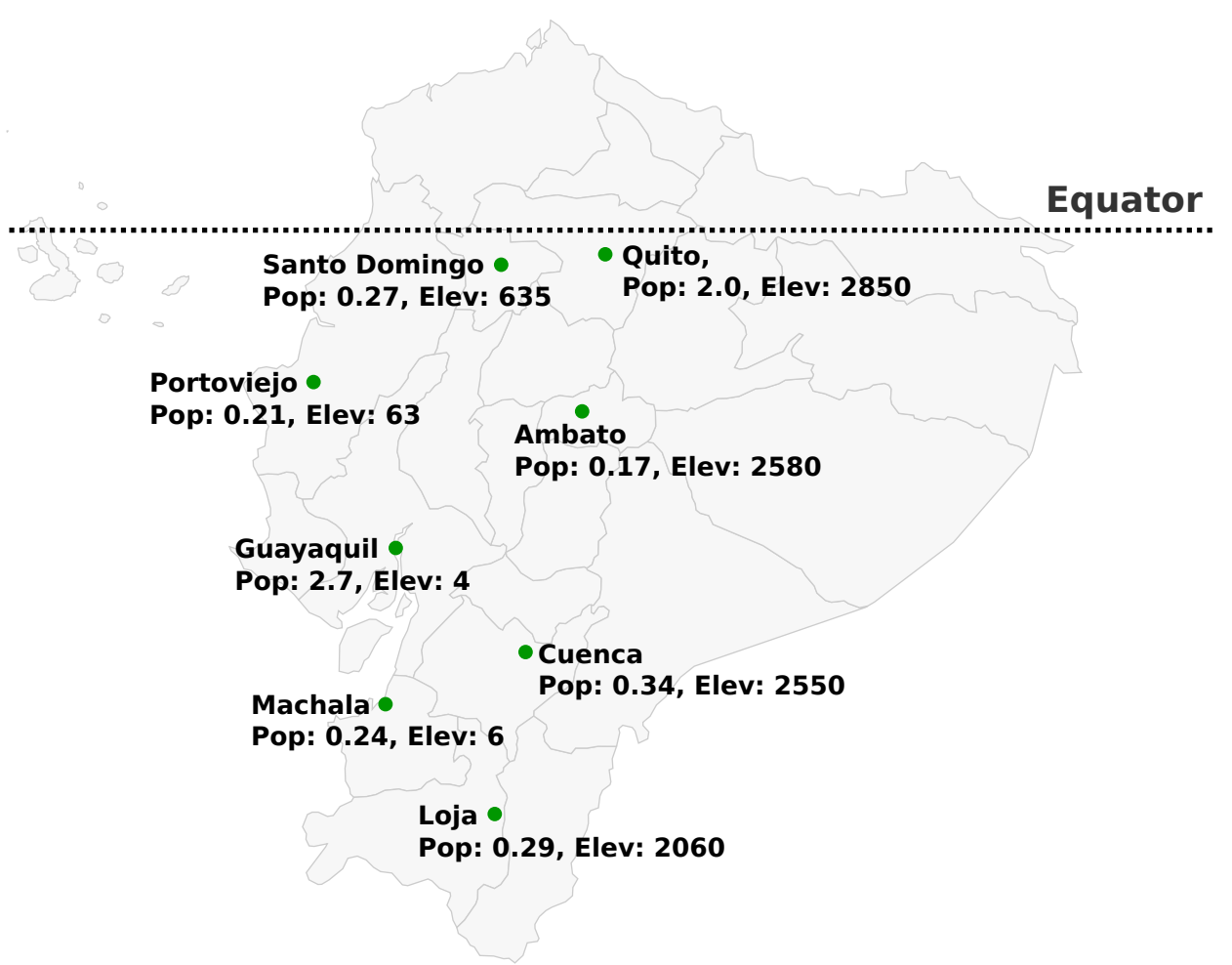

Figure 1. Map of the selected cities for the study.

The collected data from the meteorological station of the Salesian Polytechnic University in the city of Cuenca have been tabulated in a statistical and mathematical analysis computer tool for its estimation and analysis as a function of time. In this analysis, each variable's hourly and daily average has been carried out. This was performed with the data collected from 3 years spent in the meteorological station: 2016, 2017, and 2018. The following statistical analysis will be based on the variables of Global Radiation as Diffuse Radiation.

Table 2 summarizes the daily averages of each variable in the three years analyzed in the city of Cuenca, where it was found that, in 2016, the highest daily radiation was obtained with $4464.62 \mathrm{Wh} / \mathrm{m}^{2}$. The year with the highest temperature is 2018 with a value of $15.28^{\circ}$.

Table 2. Daily averages of the studied variables by year.

\begin{tabular}{|c|c|c|c|c|}
\hline Year & $\begin{array}{l}\text { Global Insolation } \\
\left(\mathrm{Wh} / \mathrm{m}^{2}\right)\end{array}$ & $\begin{array}{l}\text { Diffuse Insolation } \\
\left(\mathrm{Wh} / \mathrm{m}^{2}\right)\end{array}$ & $\begin{array}{l}\text { Direct Insolation } \\
\left(\mathrm{Wh} / \mathrm{m}^{2}\right)\end{array}$ & Mean Temperature $\left({ }^{\circ} \mathrm{C}\right)$ \\
\hline 2016 & 4464.62 & 2851.53 & 1613.09 & 14.68 \\
\hline 2017 & 4445.60 & 3275.88 & 1169.72 & 14.11 \\
\hline 2018 & 4643.90 & 3712.2 & 931.7 & 15.28 \\
\hline
\end{tabular}

Figure 2 summarizes the daily-monthly average of the studied variables, considering three years of data. It is noted that the month where there is the most significant amount of radiation is November with $5416.11 \mathrm{Wh} / \mathrm{m}^{2}$. The highest temperature was $16.47^{\circ}$, in February. 


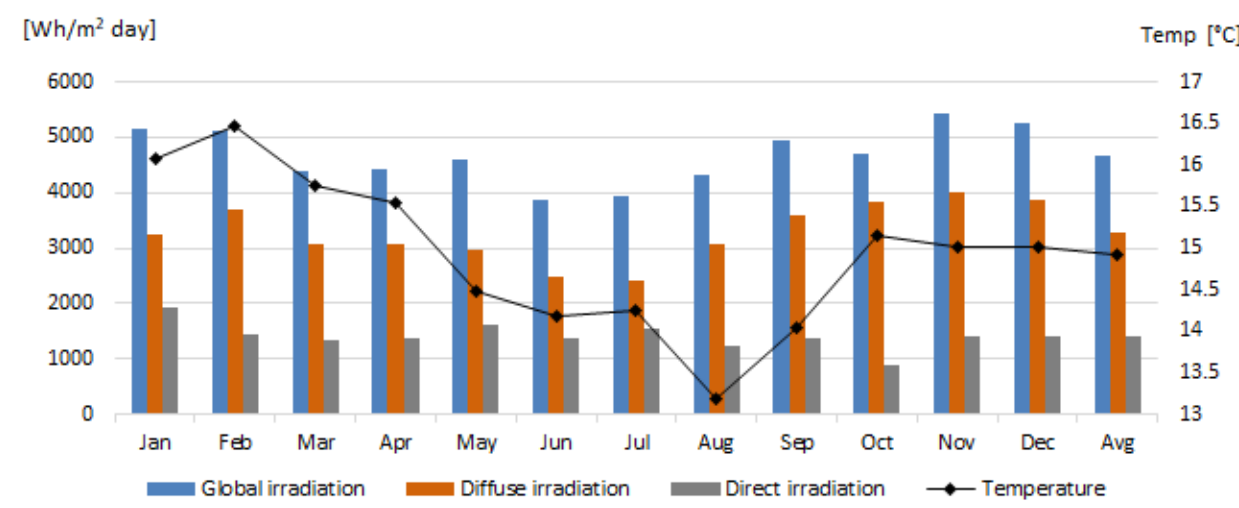

Figure 2. Monthly average of the studied variables.

For this analysis, TMY data were generated by the Geological and Energy Research Institute of Ecuador [31]. These data come from the most populated cities in Ecuador, such as Quito, Guayaquil, Cuenca, Loja, Machala, Santo Domingo, Portoviejo, and Ambato. These cities are distributed in different regions of the country.

In Figure 3, it is observed that, in the cities closest to the equator, climatic variables' influence is not significant. The rainy season coincides with solar radiation coming from the north. MATLAB software uses different models to calculate the total insolation captured for a flat surface, giving as outputs the optimal tilt and orientation angles depending on the available climatic variables.

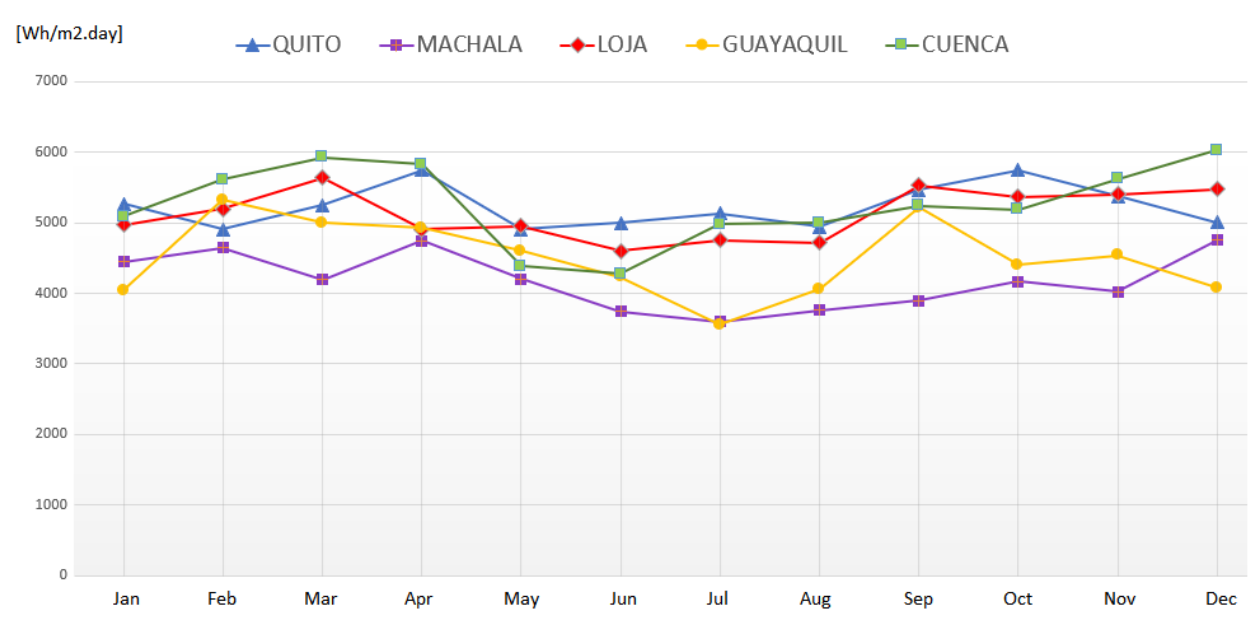

Figure 3. Monthly average of radiation in cities of Ecuador.

\subsection{Isotropic Diffuse Model}

The total solar irradiance is defined:

$$
I_{T}=I_{b} R_{b}+I_{d} R_{d}+I \rho_{g} R_{r}
$$

where $I_{b}, I_{d}, I$ are the components of beam, diffuse, and global insolation on a horizontal surface respectively, $\rho_{g}$ is the ground reflectance and $R_{b}, R_{d}$, and $R_{r}$ are their conversion factors. In this study, a constant ground reflectance $\left(\rho_{g}\right)$ of 0.2 was considered.

For this work, four models were selected to determine solar insolation on flat surfaces. The selected models are Liu and Jordan, Temps and Coulsen, Klucher, and Pérez. They were selected considering that they are widely used in solar estimation works. Moreover, these models include three common model types: isotropic, anisotropic with two components, and anisotropic with three components [21]. The description of the selected models is explained below. 


\subsection{Liu and Jordan Model}

This is a basic model that considers that all-sky diffuse sky radiation is uniform over the skydome and that reflection on the ground is diffuse. With an isotropic diffuse sky condition, the total solar irradiance $I_{T}$ is obtained [7]:

$$
I_{T}=I_{b} R_{b}+I_{d}\left(\frac{1+\cos \beta}{2}\right)+I \rho_{g}\left(\frac{1-\cos \beta}{2}\right)
$$

where $\beta$ is the angle of inclination.

\subsection{Temps and Coulson Model}

This model considers an isotropic diffuse sky but modifies the isotropic diffuse model by the sun's path. The total solar irradiance $I_{T}$ is defined [32]:

$$
I_{T}=I_{b} R_{b}+I_{d}\left(\frac{1+\cos \beta}{2}\right)\left(1+\sin ^{3} \frac{\beta}{2}\right)\left(1+\cos ^{2} \theta \sin ^{3} \theta_{z}\right)+I \rho_{g}\left(\frac{1-\cos \beta}{2}\right)
$$

where $\theta$ is the angle of incidence of the sun, and its variation throughout the day is given by the following equation and defined as per:

$$
\theta=\arccos (\sin \delta \sin \phi \cos \gamma+\cos \delta \cos \phi \cos \beta \cos \omega+\cos \delta \sin \phi \sin \beta \cos \gamma \cos \omega+\cos \delta \sin \beta \sin \gamma \sin \omega),
$$

where $\delta$ is the angle of solar declination, $\phi$ is the place latitude, $\gamma$ is the orientation angle, and $\omega$ the angle of solar hour. $\theta_{z}$ is the cenital angle and is defined as per:

$$
\theta_{z}=\arccos (\cos \phi \cos \delta \cos \omega+\sin \phi \sin \delta) .
$$

\subsection{Klucher Model}

This model modifies the Temps and Coulson model, to be able to correct estimates of conditions in cloudy skies. The total solar irradiance is calculated [33]:

$$
I_{T}=I_{b} R_{b}+I_{d}\left(\frac{1+\cos \beta}{2}\right)\left(1+F \sin ^{3} \frac{\beta}{2}\right)\left(1+F \cos ^{2} \theta \sin ^{3} \theta_{z}\right)+I \rho_{g}\left(\frac{1-\cos \beta}{2}\right),
$$

where $F$ is the modulate function to correct the Temps and Coulson model.

\subsection{Pérez Model}

Pérez's model divides diffuse insolation into three components: horizon zone, circumsolar zone and isotropic background. The diffuse irradiance is calculated [34]:

$$
I_{d, t i l t}=I_{b}\left(\frac{1+\cos \beta}{2}\right)(1-F)+F_{1} \frac{\cos \theta}{\cos \theta_{z}}+F_{2} \sin \beta,
$$

where $F_{1}$ is the circumsolar brightness coefficient, and $F_{2}$ is the horizon brightness coefficient. These variables can be calculated as per:

$$
\begin{aligned}
& F_{1}=f_{11}(\varepsilon)+\Delta f_{12}(\varepsilon)+\theta_{z} f_{13}(\varepsilon), \\
& F_{2}=f_{21}(\varepsilon)+\Delta f_{22}(\varepsilon)+\theta_{z} f_{23}(\varepsilon) .
\end{aligned}
$$

where $\epsilon$ is the sky clarity index and $\Delta$ is the brightness index.

The $f$ coefficients are summarized in Table 3 . 
Table 3. Coefficients of the Pérez model.

\begin{tabular}{ccccccc}
\hline \multirow{2}{*}{$\boldsymbol{f}$} & \multicolumn{7}{c}{ Coefficients $f$} \\
\cline { 2 - 7 } & $\mathbf{f ~ 1 1}$ & $\mathbf{f ~ 1 2}$ & $\mathbf{f ~ 1 3}$ & $\mathbf{f ~ 2 1}$ & $\mathbf{f ~ 2 2}$ & $\mathbf{f ~ 2 3}$ \\
\hline $0-1.065$ & -0.008 & 0.58 & -0.062 & -0.06 & 0.072 & -0.022 \\
\hline $1.065-1.23$ & 0.13 & 0.683 & -0.151 & -0.019 & 0.06 & -0.029 \\
\hline $1.23-1.5$ & 0.33 & 0.487 & -0.221 & 0.055 & -0.015 & -0.026 \\
\hline $1.5-1.95$ & 0.568 & 0.188 & -0.295 & 0.109 & -0.152 & -0.014 \\
\hline $1.95-2.8$ & 0.873 & -0.392 & -0.362 & 0.226 & -0.462 & 0.001 \\
\hline $2.8-4.5$ & 1.13 & -1.237 & -0.412 & 0.288 & -0.823 & 0.056 \\
\hline $4.5-6.2$ & 1.06 & -1.6 & -0.359 & 0.264 & -1.127 & 0.131 \\
\hline$>6.2$ & 0.678 & -0.327 & -0.25 & 0.156 & -1.377 & 0.251 \\
\hline
\end{tabular}

Then, in order to find the total irradiance, the following equation is considered:

$$
I_{T}=I_{b} R_{b}+I_{d, t i l t}+I \rho_{g}\left(\frac{1-\cos \beta}{2}\right)
$$

The MATLAB software was used to develop an application that provides all the necessary tools to thoroughly analyze the data for the development of the application. Usually, a large amount of data is needed to obtain a higher value of exact maximum insolation on a flat surface. Moreover, the tool meshgrid, pol2cart, and contourf of MATLAB were used to produce the solar geometry ancillary data for different models.

\section{Results and Discussion}

\subsection{Optimal Tilt and Orientation Angles}

The developed application obtains a flat surface's optimal position to capture solar energy in a given location. The results are based on the climate data introduced for each city (8760 h each year). Figures 4 and 5 illustrate the captured irradiance on a flat surface in Cuenca-Ecuador according to the Klucher model.

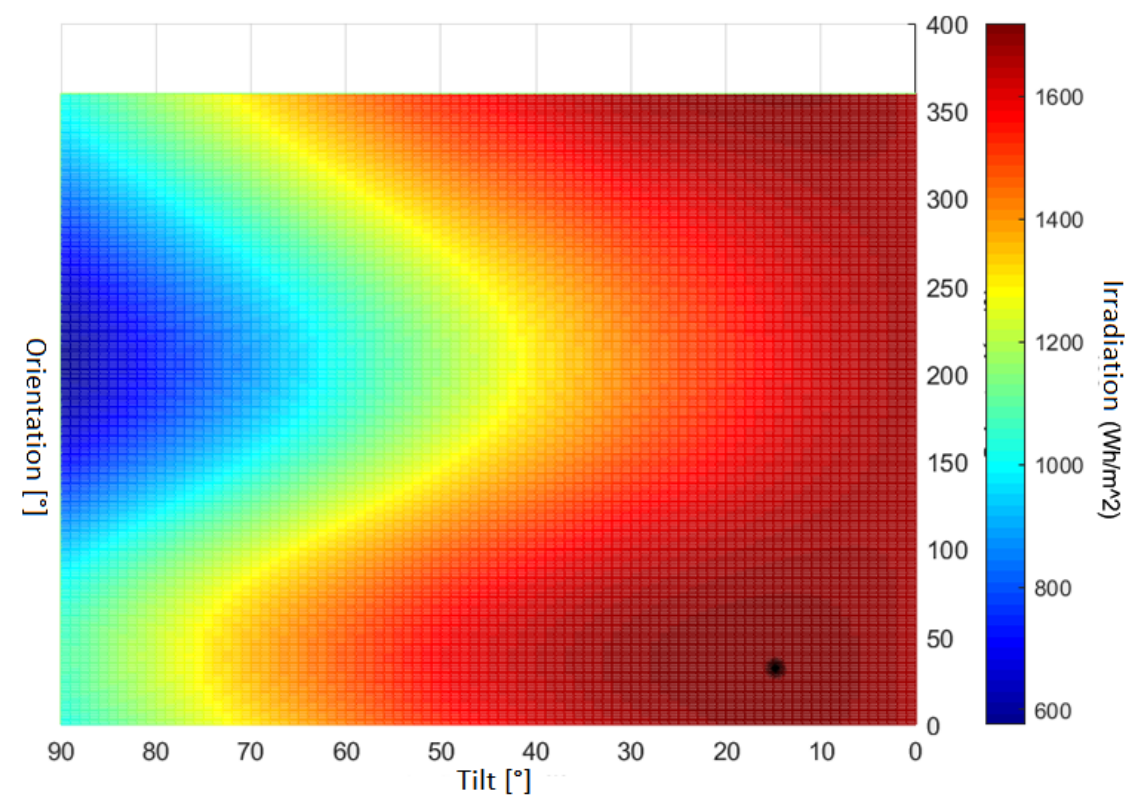

Figure 4. Captured irradiance on a flat surface in Cuenca-Ecuador according to the Klucher model (2D view). 


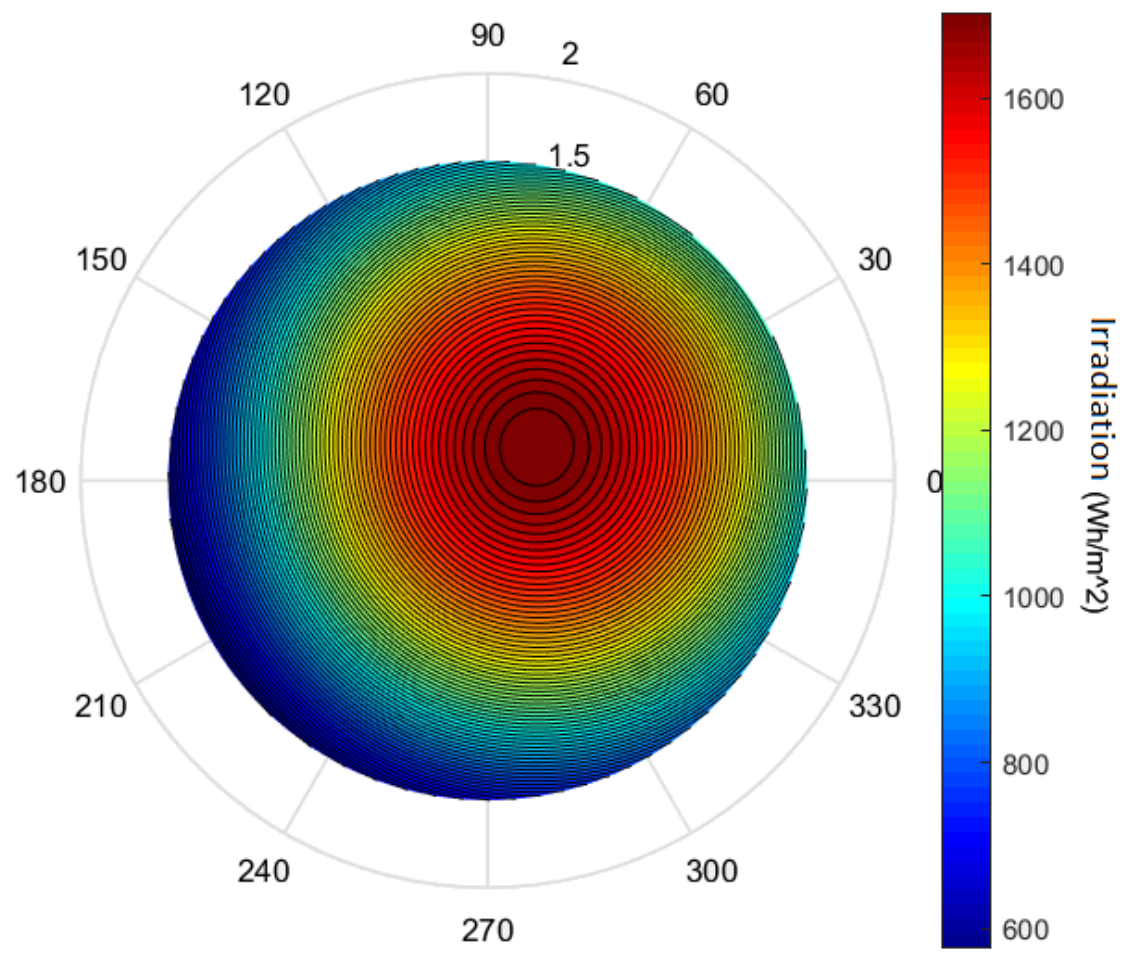

Figure 5. Captured irradiance on a flat surface in Cuenca-Ecuador according to the Klucher model. $\left(0-360^{\circ}\right.$ angle concerning the north, while the radius is the tilt angle in radians).

Figure 6 depicts the captured irradiance on a flat surface in Cuenca-Ecuador according to the Liu and Jordan model, and Figure 7 depicts the captured irradiance on a flat surface in Cuenca-Ecuador according to the Temps model. With the mathematical models that have been analyzed through the application, similar results were obtained for the city of Cuenca with the measured data. Note that, for this locality, the more significant capture of solar insolation on a flat surface has an orientation of $34^{\circ}$ concerning the north and an inclination angle of $16^{\circ}$.

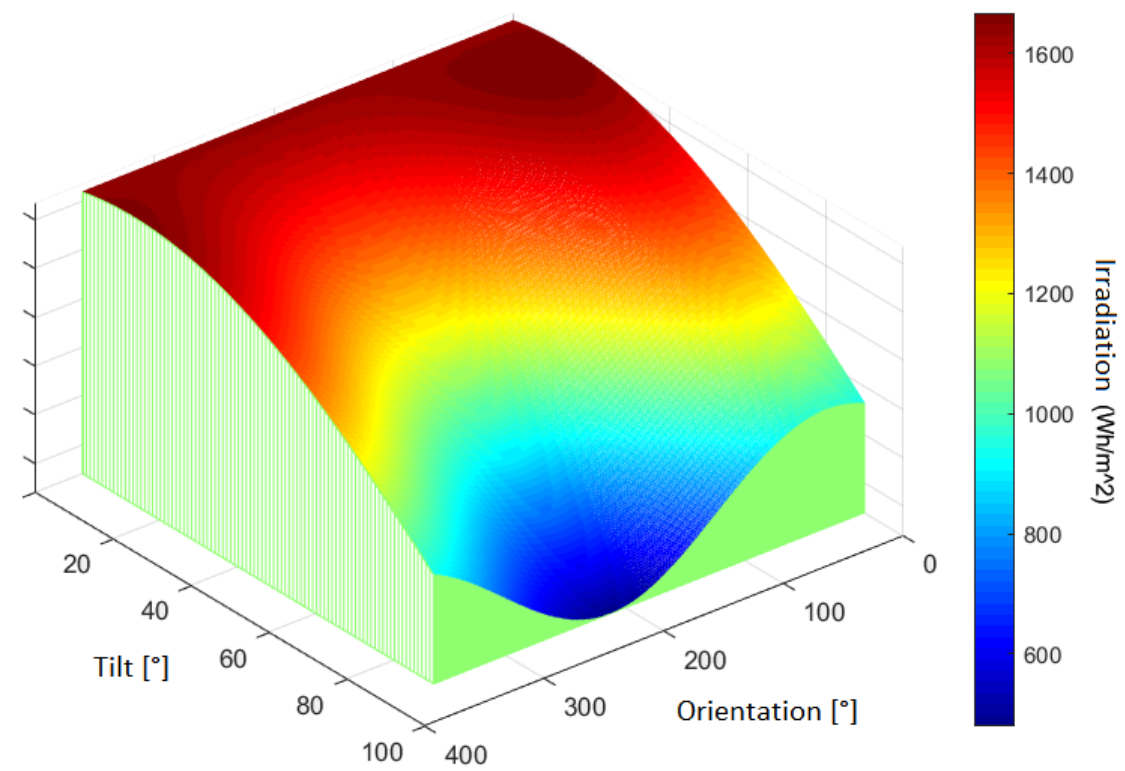

Figure 6. Captured irradiance on a flat surface in Cuenca-Ecuador according to the Liu and Jordan model. 


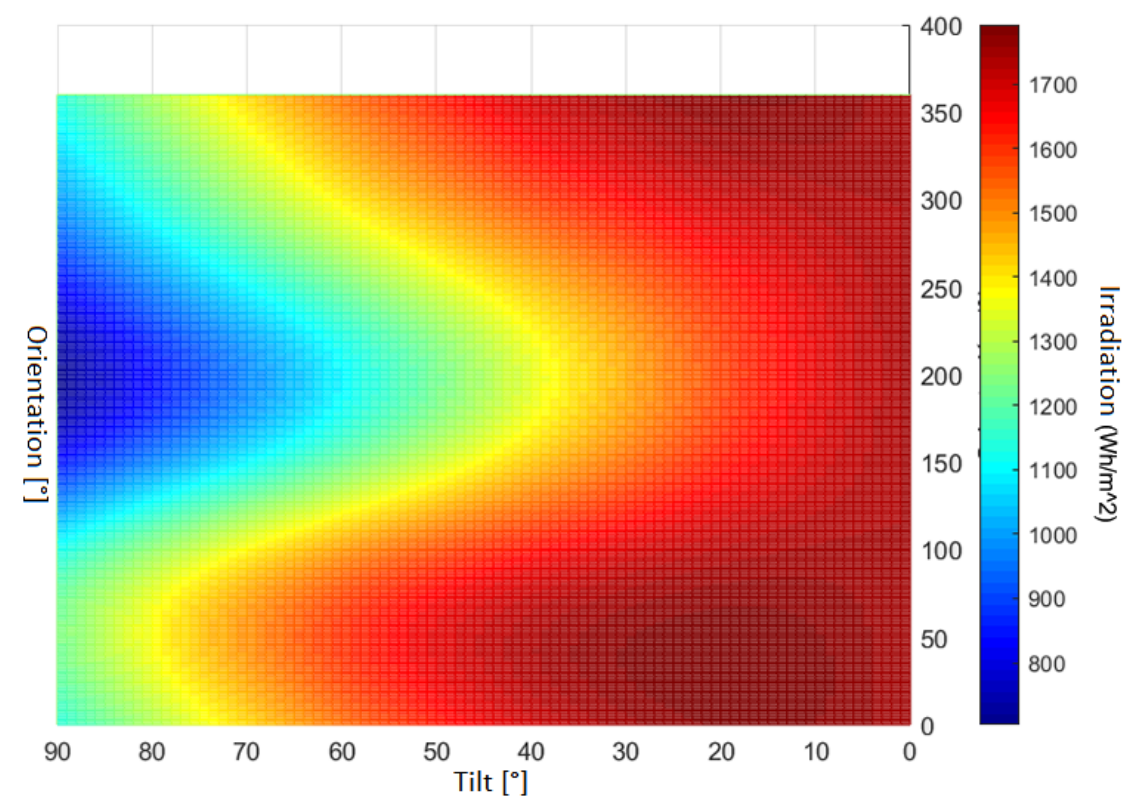

Figure 7. Captured irradiance on a flat surface in Cuenca-Ecuador according to the Temps model.

The five mathematical models obtain the optimal inclinations and orientations to capture solar irradiation. However, it is essential to consider that the Klucher and Pérez models are the most complex and, at the same time, the ones that best adjust to real conditions since they improve the previously existing models. In the case of the Klucher model, it has been selected since it is based on the excellent prediction for clear sky conditions of Temps and Coulson model but with the addition of a "modulating function" to correct it under conditions cloudy sky and thus have greater precision in values of this climatic condition. On the other hand, Pérez's model is based on a detailed statistical analysis of the diffuse sky, dividing it into three components: horizon zone, circumsolar zone, and isotropic bottom.

On the other hand, with the TMY data, different results were obtained for Ecuador's cities, as shown in Tables 4 and 5 .

Table 4. Obtained values for diffuse isotropic, Liu and Jordan, and Temps and Coulson models.

\begin{tabular}{lcccccccccc}
\hline \multicolumn{8}{c}{ Irradiance, Inclination, and Orientation Values } \\
\hline Models & \multicolumn{3}{c}{ Diffuse Isotropic } & \multicolumn{3}{c}{ Liu and Jordan } & \multicolumn{4}{c}{ Temps and Coulson } \\
\hline Cities & $\left(\mathrm{Wh} / \mathrm{m}^{2}\right)$ & $\mathrm{I}\left(^{\circ}\right)$ & $\mathrm{O}\left(^{\circ}\right)$ & $\left(\mathrm{Wh} / \mathrm{m}^{2}\right)$ & $\mathrm{I}\left(^{\circ}\right)$ & $\mathrm{O}\left({ }^{\circ}\right)$ & $\left(\mathrm{Wh} / \mathrm{m}^{2}\right)$ & $\mathrm{I}\left({ }^{\circ}\right)$ & $\mathrm{O}\left(^{\circ}\right)$ \\
Guayaquil & 1823.064 & 18 & 50 & 1823.064 & 18 & 50 & 1935.033 & 21 & 51 \\
Quito & 2089.807 & 17 & 35 & 2089.837 & 18 & 35 & 2187.17 & 19 & 35 \\
Cuenca & 2184.402 & 18 & 34 & 2184.402 & 18 & 36 & 2282.8 & 20 & 36 \\
Santo & 1628.135 & 17 & 46 & 1367.136 & 17 & 46 & 1729.643 & 19 & 47 \\
Domingo & & & & & & & & & \\
Machala & 1732.026 & 19 & 51 & 1732.026 & 19 & 51 & 1843.007 & 22 & 52 \\
Portoviejo & 1894.892 & 20 & 53 & 1895.89 & 20 & 53 & 2008.308 & 23 & 53 \\
Loja & 2159.481 & 19 & 40 & 2159.481 & 20 & 40 & 2259.794 & 21 & 40 \\
Ambato & 2120.749 & 19 & 38 & 2120.749 & 19 & 38 & 2218.019 & 20 & 38 \\
\hline & & & & & & & & &
\end{tabular}


Table 5. Obtained values for Klucher and Pérez models.

\begin{tabular}{ccccccc}
\hline \multicolumn{6}{c}{ Irradiance, Inclination, and Orientation Values } \\
\hline Models & \multicolumn{3}{c}{ Klucher } & \multicolumn{3}{c}{ Pérez } \\
\hline Cities & $\left(\mathrm{Wh} / \mathrm{m}^{2}\right)$ & $\mathrm{I}\left(^{\circ}\right)$ & $\mathrm{O}\left(^{\circ}\right)$ & $\left(\mathrm{Wh} / \mathrm{m}^{2}\right)$ & $\mathrm{I}\left(^{\circ}\right)$ & $\mathrm{O}\left(^{\circ}\right)$ \\
Guayaquil & 1878.34 & 20 & 51 & 1777.555 & 23 & 52 \\
Quito & 2142.09 & 18 & 35 & 2456.078 & 17 & 38 \\
Cuenca & 2240.651 & 19 & 36 & 2627.494 & 18 & 37 \\
Santo Domingo & 1671.294 & 18 & 47 & 1551.653 & 22 & 49 \\
Machala & 1783.287 & 20 & 52 & 1644.508 & 25 & 53 \\
Portoviejo & 1952.73 & 21 & 53 & 1895.283 & 24 & 54 \\
Loja & 2217.426 & 21 & 40 & 2561.746 & 22 & 38 \\
Ambato & 2175.057 & 19 & 38 & 2521.848 & 18 & 39 \\
\hline
\end{tabular}

From the mathematical models, each city's variation in Ecuador is clearly shown, taking into account the typical year files' error. Note that these values are taken with a $-1 \%$ margin of the maximum insolation value to obtain tilt and orientation range results closer to the measured data values.

\subsection{Assessment of the Selected Models}

The study used data obtained in 3 years from the city of Cuenca through the Salesian Polytechnic University's meteorological station (real-data were taken every hour for three years). To minimize the errors, data from the city of Cuenca were used in a TMY file. Its source is an estimate based on data collected by satellite of previous years.

A comparison and post evaluation of this type of file is carried out together with the data or values measured locally by Ecuador's meteorological stations. It will be essential to know what percentages of effectiveness have this type of file and present a comparison based on the models proposed for various Ecuador cities.

Figure 8 shows the difference in insolation and inclination between the measured data and a TMY, with a margin of error in the insolation of $19.11 \%$ and in the inclination of $22.2 \%$. These values are obtained from the error percentage formula, with a $-1 \%$ margin of the maximum insolation value in each case. These results are in concordance with Reference [35], where it is indicated that the difference between measured data and TMY data is between $8.89 \%$ and $23.75 \%$.

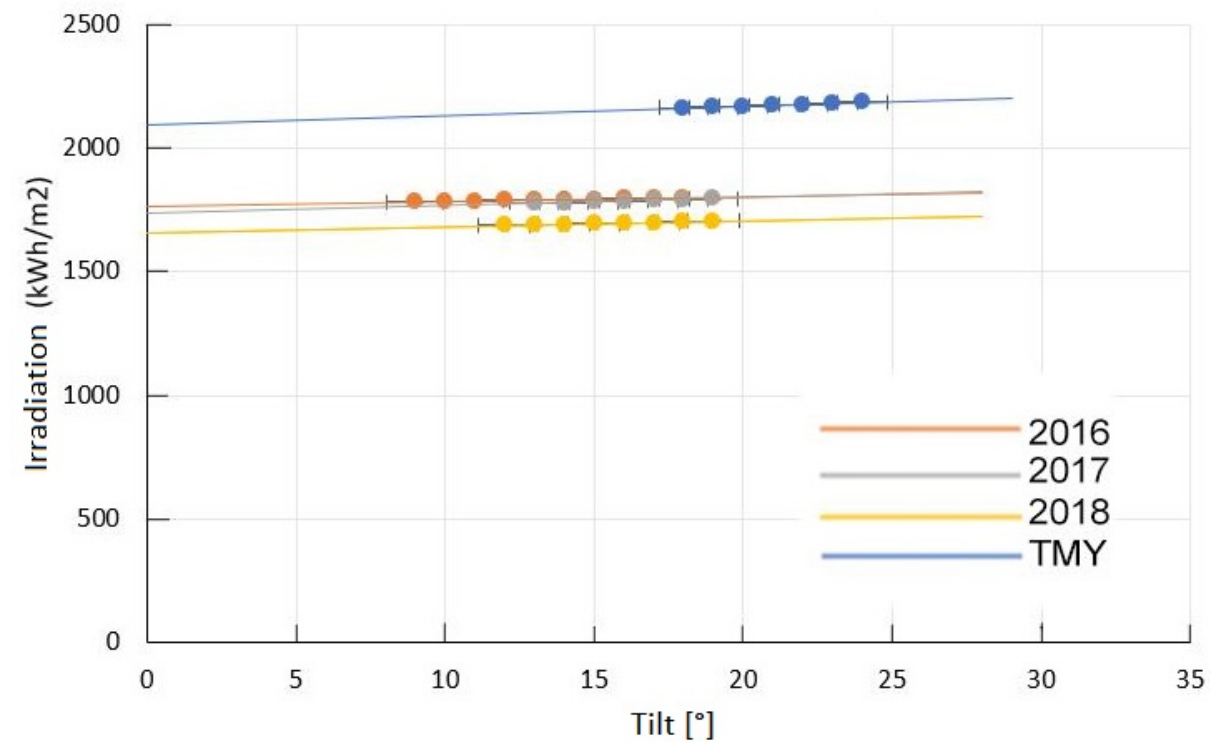

Figure 8. Solar insolation as a function of the tilt of a north facing flat surface in Cuenca (measured data vs. TMY data). 


\subsection{Recommendations for the Optimal Orientation in Ecuador}

The available literature indicates that countries located in the northern hemisphere should orient their solar panels or modules towards the southern hemisphere, and vice versa for the countries located in the southern hemisphere. This is not the case for countries situated in the equator, where some works, such as Reference [36], suggest that the inclination should be $0^{\circ}$. However, other works suggests that the inclination angle should not be less than $5^{\circ}$ to avoid dirtiness on the PV panels. Moreover, other works demonstrated that, in Quitoand Latacunga, an angle higher than $30^{\circ}$ will result in significant losses $[37,38]$.

Similarly, the authors of Reference [39] analyzed various inclination angles in Cuenca (from $0^{\circ}$ to $30^{\circ}$ ) and evidenced that the losses become significant close to $30^{\circ}$.

The authors of Reference [40] establish that the PV system site has a higher annual generation as it faces east with a slope close to the horizontal, but without significant differences with respect to the rest of the orientations with similar slopes. This indicates that, in equatorial latitudes, the inclination and orientation is not an important limitation in the production of energy based on solar systems, as it happens in higher latitudes, such as those of Europe, the United States, Argentina, or Australia.

Thus, each author has it own criteria to select the optimal orientation and inclination angles. In this work, the optimal angles of the most populated cities were obtained based on the presented models.

\subsection{Discussion}

Since existing real-data from solar irradiance was used in these existing mathematical models, one can assume adequate results. The uncertainty derived from the input data on the model should then be assessed before the model output is assessed.

Particular technical challenges need to be considered to implement the optimal tilt and orientation angles while installing PVs, such as physical space availability and ideal installation conditions with shadow-free.

Although the presented models and others could present accurate results for tilt and orientation angles in fixed flat surfaces, it is crucial to note that some input parameters could have a strong influence on the irradiance data. For example, other parameters, such as relative humidity, cloud coverage, and cloud base, could impact irradiance data, which could be taken into account in future works.

Observe also that anisotropic methods could be unable to mimic the anisotropy of real skies, especially partly cloudy skies or those observed under elevated turbidity conditions. Thus, various accurate solutions exist to model spectral/broadband irradiance on sloped surfaces, such as the Unisky Simulator [41]. This tool provides the maps of zenith-normalized spectral sky radiances and can model random distributions, as well as statistical averaging over random distributions [42].

Optimum tilt angle strongly depends on momentary cloudiness and turbidity conditions. Aerosols can change the angular distribution of scattered electromagnetic radiation significantly. For instance, a forward-lobed scattering is typical for large particles, while the ratio of side-to-forward scattering increases as the particles become smaller in size. Therefore, knowledge of particle size distribution (or at least PM1.0) may be crucial to understanding diffuse light distribution dynamics.

For a country, such as Ecuador, where there are significant changes in weather conditions across cities due to geographic conditions, it is not representative for the entire country to estimate a single average optimum tilt angle.

Overall, the results obtained indicate that, in Ecuador, the optimum inclination of a flat surface should be between $12^{\circ}$ and $19^{\circ}$ concerning the horizontal and the orientation between $20^{\circ}$ and $60^{\circ}$ concerning the North. However, although the results are congruent, the results would be more reliable with data measured in all cities since the TMY data could generate inaccuracies in the results. Additionally, in this work, the authors do not model hypothetically idealized skies. 


\title{
4. Conclusions
}

This paper presents a computer application that determines the optimal tilt and orientation angles of flat surfaces to maximize solar insolation capture based on existing mathematical models. The most populated cities of Ecuador were selected for this study, since there are significant changes in weather conditions across cities due to geographic conditions, and it is not representative for the entire country to estimate a single average optimum tilt angle. The data was obtained through meteorological stations. The city of Cuenca was selected as a reference, and its data measured during three years from the local meteorological stations, comparing them with the TMY files of the same. Significant variations were observed in the various selected cities in all the variables studied. It should be noted that the typical year files are a database without updating and that their content will significantly affect the simulations and calculations carried out. Note that the most common and studied climate scenario currently predicts an increase between $1 \%$ and $3.49 \%$ in annual mean global temperatures.

The error in TMY files (which ranges between $22.2 \%$ in inclination and $19.11 \%$ in insolation values) must be taken into account while modeling. It is observed that the cities of the Sierra region-Quito, Cuenca, Loja, and Ambato-have a higher insolation index than the cities of the Costa region: Guayaquil, Santo Domingo, Machala, and Portoviejo. In this study, the inclination and orientation values together with those of maximum irradiance analyzed with data measured from meteorological stations have primarily coincided with other studies carried out mainly in the city of Cuenca, where the optimal inclination of a flat surface for maximizing insolation pickup is between $9^{\circ}$ and $16^{\circ}$, and orientation between $20^{\circ}$ and $60^{\circ}$.

In a future work, it could be helpful to analyze the effects of orientation and irradiance on DC power.

Author Contributions: Conceptualization, X.S.-G.; Data curation, E.C., J.-J.F.; Formal analysis, E.C., J.-J.F.; Investigation, E.C., J.-J.F.; Methodology, X.S.-G., E.C., J.-J.F.; Supervision, X.S.-G.; Validation, X.S.-G., A.B.-E., J.-M.C.; Writing—original draft, E.C., J.-J.F., J.-M.C.; Writing—review \& editing, X.S.-G., A.B.-E., J.-M.C. All authors have read and agreed to the published version of the manuscript.

Funding: The APC was funded by Universidad de las Américas-Ecuador.

Institutional Review Board Statement: Not applicable.

Informed Consent Statement: Not applicable.

Data Availability Statement: Data available on request due to restrictions eg privacy or ethical.

Conflicts of Interest: The authors declare no conflict of interest.

\author{
Abbreviations \\ TMY Typical Meteorological Years \\ PV Photovoltaic \\ RE Renewable Energy
}

The following abbreviations are used in this manuscript:

\section{References}

1. Izquierdo-Torres, I.F.; Pacheco-Portilla, M.G.; Gonzalez-Morales, L.G.; Zalamea-Leon, E.F. Simulacion fotovoltaica considerando parametros de integracion en edificaciones. Ingenius. Revista de Ciencia y Tecnología 2019, 21, 21-31. [CrossRef]

2. Clairand, J.M.; Álvarez-Bel, C.; Rodríguez-García, J.; Escrivá-Escrivá, G. Impact of Electric Vehicle Charging Strategy on the Long-Term Planning of an Isolated Microgrid. Energies 2020, 13, 3455. [CrossRef]

3. Travaillé, P.; Benamar, A.; Clairand, J.M.; Escrivá-Escrivá, G. Operation of DC Microgrids Considering Different Strategies of Electric Vehicle Charging. In Proceedings of the 2020 IEEE ANDESCON, Quito, Ecuador, 13-16 October 2020; pp. 1-5. [CrossRef]

4. Spencer, J.W. Fourier series reprensentation of the position of the sun. Search 1971, 2, 172.

5. Erbs, D.G.; Klein, S.A.; Duffie, J.A. Estimation of the diffuse radiation fraction for hourly, daily and monthly-average global radiation. Sol. Energy 1982, 28, 293-302. [CrossRef]

6. Reindl, D.T.; Beckman, W.A.; Duffie, J.A. Diffuse fraction correlations. Sol. Energy 1990, 45, 1-7. [CrossRef] 
7. Liu, B.; Jordan, R. Daily insolation on surfaces tilted towards equator. ASHRAE J. 1961, 10.

8. Hay, J.E. Calculation of monthly mean solar radiation for horizontal and inclined surfaces. Sol. Energy 1979, 23, 301-307. [CrossRef]

9. Gueymard, C. An anisotropic solar irradiance model for tilted surfaces and its comparison with selected engineering algorithms. Sol. Energy 1987, 38, 367-386. [CrossRef]

10. Kambezidis, H.D.; Psiloglou, B.E.; Gueymard, C. Measurements and models for total solar irradiance on inclined surface in Athens, Greece. Sol. Energy 1994, 53, 177-185. [CrossRef]

11. Housmans, C.; Ipe, A.; Bertrand, C. Tilt to horizontal global solar irradiance conversion: An evaluation at high tilt angles and different orientations. Renew. Energy 2017, 113, 1529-1538. [CrossRef]

12. Khan, R.A.; Mahmood, M.R.; Haque, A. Enhanced energy extraction in an open loop single-axis solar tracking PV system with optimized tracker rotation about tilted axis. J. Renew. Sustain. Energy 2018, 10. [CrossRef]

13. Halilovic, S.; Bright, J.M.; Herzberg, W.; Killinger, S. An analytical approach for estimating the global horizontal from the global tilted irradiance. Sol. Energy 2019, 188, 1042-1053. [CrossRef]

14. Campana, P.E.; Landelius, T.; Andersson, S.; Lundström, L.; Nordlander, E.; He, T.; Zhang, J.; Stridh, B.; Yan, J. A gridded optimization model for photovoltaic applications. Sol. Energy 2020, 202, 465-484. [CrossRef]

15. Gómez-Uceda, F.J.; Moreno-Garcia, I.M.; Jiménez-Martínez, J.M.; López-Luque, R.; Fernández-Ahumada, L.M. Analysis of the influence of terrain orientation on the design of pv facilities with single-axis trackers. Appl. Sci. 2020, 10, 8531. [CrossRef]

16. Wattan, R.; Janjai, S. An investigation of the performance of 14 models for estimating hourly diffuse irradiation on inclined surfaces at tropical sites. Renew. Energy 2016, 93, 667-674. [CrossRef]

17. Ihaddadene, N.; Ihaddadene, R.; Charik, A. Best Tilt Angle of Fixed Solar Conversion Systems at M'Sila Region (Algeria). Energy Procedia 2017, 118, 63-71. [CrossRef]

18. Koussa, M.; Saheb-Koussa, D.; Hadji, S. Experimental investigation of simple solar radiation spectral model performances under a Mediterranean Algerian's climate. Energy 2017, 120, 751-773. [CrossRef]

19. Raptis, P.I.; Kazadzis, S.; Psiloglou, B.; Kouremeti, N.; Kosmopoulos, P.; Kazantzidis, A. Measurements and model simulations of solar radiation at tilted planes, towards the maximization of energy capture. Energy 2017, 130, 570-580. [CrossRef]

20. Seme, S.; Sredenšek, K.; Štumberger, B.; Hadžiselimović, M. Analysis of the performance of photovoltaic systems in Slovenia. Sol. Energy 2019, 180, 550-558. [CrossRef]

21. Mubarak, R.; Hofmann, M.; Riechelmann, S.; Seckmeyer, G. Comparison of modelled and measured tilted solar irradiance for photovoltaic applications. Energies 2017, 10, 1688. [CrossRef]

22. Nassar, Y.F.; Hafez, A.A.; Alsadi, S.Y. Multi-Factorial Comparison for 24 Distinct Transposition Models for Inclined Surface Solar Irradiance Computation in the State of Palestine: A Case Study. Front. Energy Res. 2020, 7, 1-19. [CrossRef]

23. Toledo, C.; Amillo, A.M.G.; Bardizza, G.; Abad, J.; Urbina, A. Evaluation of solar radiation transposition models for passive energy management and building integrated photovoltaics. Energies 2020, 13, 702. [CrossRef]

24. Costa, S.C.; Kazmerski, L.L.; Diniz, A.S.A. Estimate of Soiling Rates Based on Soiling Monitoring Station and PV System Data: Case Study for Equatorial-Climate Brazil. IEEE J. Photovoltaics 2021, 11, 461-468. [CrossRef]

25. Trewin, B. The climates of the tropics and how they are changing. State Trop. 2014, 1, 39-52.

26. Bykerk-Kauffman, A. Seasons and Why the Equator is Warmer Than the Poles. Pedagogy in Action the SERC Portal for Educators. Sci. Educ. Resour. Center. 2018. Available online: https//goo.gl/vsDCFB (accessed on 9 May 2021).

27. Serrano-Guerrero, X.; Escrivá-Escrivá, G.; Luna-Romero, S.; Clairand, J.M. A Time-Series Treatment Method to Obtain Electrical Consumption Patterns for Anomalies Detection. Energies 2020. [CrossRef]

28. IRENA. A World of Renewables. Int. Renew. Energy Agency 2006, 1-68. Available online: https://www.irena.org/-/media/Files/ IRENA/Agency/Publication/2015/IRENA_GlobalAtlas_World_of_Renewables_2015.pdf (accessed on 9 May 2021).

29. Serrano, X.; Narváez, M.; Urigüen, C.; Escrivá-Escrivá, G. Quantitative assessment of hybrid systems of heating domestic water based on solar energy in andean zones of Ecuador. In Proceedings of the 2016 51st International Universities Power Engineering Conference (UPEC), Coimbra, Portugal, 6-9 September 2016; pp. 1-6.

30. Serrano-Guerrero, X.; Alvarez-Lozano, D.; Romero, S.F.L. Influence of local climate on the tilt and orientation angles in fixed flat surfaces to maximize the capture of solar irradiation: A case study in Cuenca-Ecuador. In Proceedings of the 2019 IEEE International Autumn Meeting on Power, Electronics and Computing (ROPEC), Guerrero, Mexico, 13-15 November 2019; pp. 1-6.

31. Instituto de Investigación Geológico y Energético-Ecuador. Available online: https:/ /www.geoenergia.gob.ec/ (accessed on 9 May 2021).

32. Temps, R.C.; Coulson, K.L. Solar radiation incident upon slopes of different orientations. Sol. Energy 1977, 19, 179-184. [CrossRef]

33. Klucher, T.M. Evaluation of models to predict insolation on tilted surfaces. Sol. Energy 1979, 23, 111-114. [CrossRef]

34. Perez, R.; Ineichen, P.; Seals, R.; Michalsky, J.; Stewart, R. Modeling daylight availability and irradiance components from direct and global irradiance. Sol. Energy 1990, 44, 271-289. [CrossRef]

35. Rudniak, J. Comparison of local solar radiation parameters with data from a typical meteorological year. Therm. Sci. Eng. Prog. 2020, 16, 100465. [CrossRef]

36. Li, D.H.W.; Lam, T.N.T. Determining the optimum tilt angle and orientation for solar energy collection based on measured solar radiance data. Int. J. Photoenergy 2007, 2007, 1-9. [CrossRef] 
37. Peña Ortiz, P.A.; Pinos Vergara, F.S. Parametrización de los sistemas eléctricos fotovoltaicos basados en las condiciones climáticas de la ciudad de Cuenca, aplicados en la Universidad Politécnica Salesiana. 2014. Available online: https://dspace.ups.edu.ec/ handle/123456789/7123 (accessed on 9 May 2021).

38. Pabón, L.; Tonato, D. Diseño e Implementación de un Sistema Eléctronico para Trazar el Perfil de Radiación Solar en la Terraza del Edificio C de la ESPE Latacunga Mediante Paneles Solares Fijo y Movil. Esc. Politécnica del Ejército extensión Latacunga 2012, 1-200.

39. Barragán-Escandón, E.A.; Zalamea-León, E.F.; Terrados-Cepeda, J.; Vanegas-Peralta, P.F. Energy self-supply estimation in intermediate cities. Renew. Sustain. Energy Rev. 2020, 129, 109913. [CrossRef]

40. Torres, I.F.I.; Portilla, M.G.P. Evaluación de la Eficiencia de Paneles Solares como Sistema de Captación de Energía Para Edificaciones del área Urbana de Cuenca. 2017. Available online: https://dspace.ucuenca.edu.ec/handle/123456789/27386 (accessed on 9 May 2021).

41. Kocifaj, M.; Fecko, S. UniSky Simulator. 2014. Available online: http:/ / www.unisky.sav.sk/?lang=en\&page=aplikacia (accessed on 9 May 2021).

42. Kocifaj, M. Unified model of radiance patterns under arbitrary sky conditions. Sol. Energy 2015, 115, 40-51. [CrossRef] 